\title{
Explanation and Remarks on Publishing
}

1. This book is an original monograph on Botanical Garden Science. Quotations from other sources are clearly marked in the text. Primary reference works and related papers are listed at the end of each chapter. Photos and pictures are sorted by chapter.

2. There are more than 2,000 photos in the book. Other than the photos taken by the authors, all rest photos provided by personnel of Nanjing Botanical Garden Mem. Sun Yat-Sen are clearly marked with the name of the provider. The photos by courtesy of domestic and foreign botanical gardens are marked with the name of photographer and/or address of the provider. Only the address of the provider was marked when the author's name was unknown.

3. For consistency and brevity, the author citation of Latin names was omitted. The names of plants were basically subject to Flora Republicae Popularis Sinicae.

4. To minimize the length of place names, the words 'province' and 'autonomous district' are omitted. For example, 'Jiangsu Province' is shortened to 'Jiangsu' and 'Guangxi Zhuang Autonomous District' is shortened to 'Guangxi'.

5. During the development of this book, many colleagues working at botanical gardens in our country kindly offered their assistance. Valuable information and excellent photos are courtesy of domestic and foreign botanical gardens and their experts are very much appreciated. A complete list of names of those who have helped the authors with this work would be impossible to be shown because of the numerous personnel. We wish to thank all of them for their valuable input. In particular, Dr. LI Ya wrote the plant information management section in Chapter 3; JI Jinyu drew numerous graphs; HE Fan, LI Yajing, WEI Jiguang and XIA Ruhong helped in the manuscript processing. We gratefully acknowledge encouragement from academician HONG Deyuan, researcher LU Anmin, HU Qiming, ZHENG Zhong, ZHANG Lianquan, YU Zhizhou, XU Tianquan and GUAN Kaiyun, etc., during the publishing process.

6. As of the time this work was finished, the lead author has been working in botanical gardens for 50 years. Numerous teachers' and friends' help, advice, urgings, and expectations were treasured up in his memory and he has nothing to give them as a reward. This book is dedicated to teachers and friends who are concerned about botanical garden business. It is a pity that the old comrade, Party Secretary LI Ming, who threw herself into the construction of Nanjing Botanical Garden, passed away in the spring of 2003, and the book was completed without her valuable comments.

7. The authors especially appreciate a group of experts and assistants for their efforts in translating and editing the Chinese version of the book into the English version. The lead editors are Mr. GORHAM John, and Associate Prof. LIU Yulan. The assistants include XU Zenglai, LI Xinhua, WEI Jiguang, ZHANG Ming, ZHANG Yuchun, LI Mei, BAI Yiren and colleagues of the Translation and Editing Office, Chinese Agricultural Academy. Without their contribution it is impossible to have the book appearing in front of readers in English. 


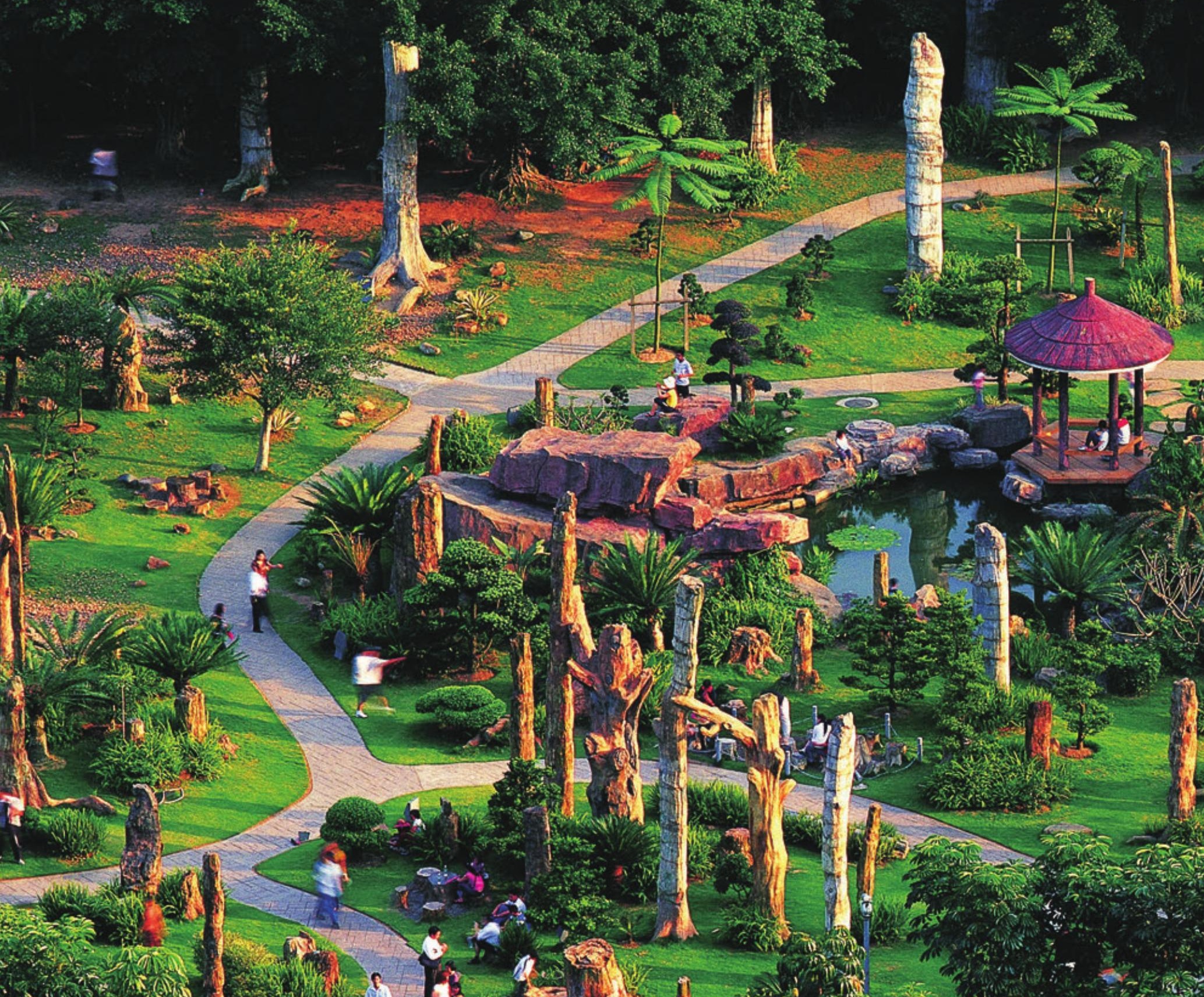

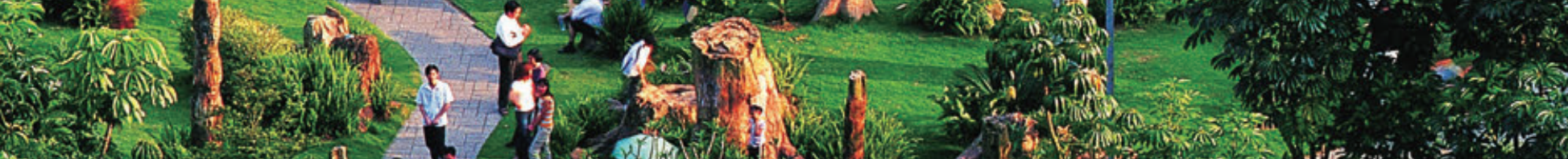

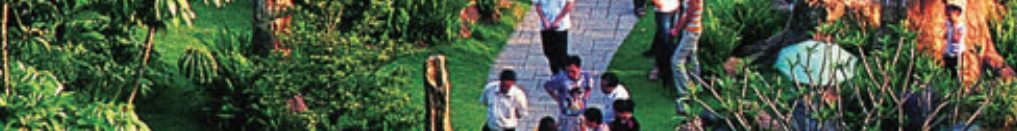

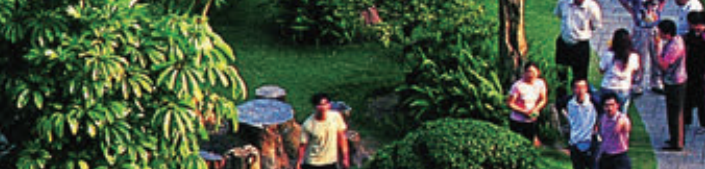

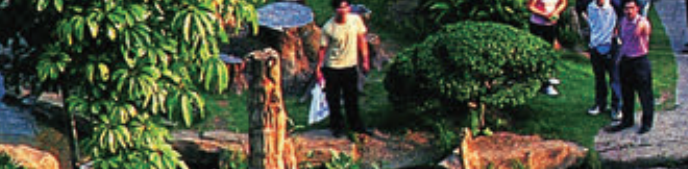

4avy 1 ?

th $15 \sqrt{5}$

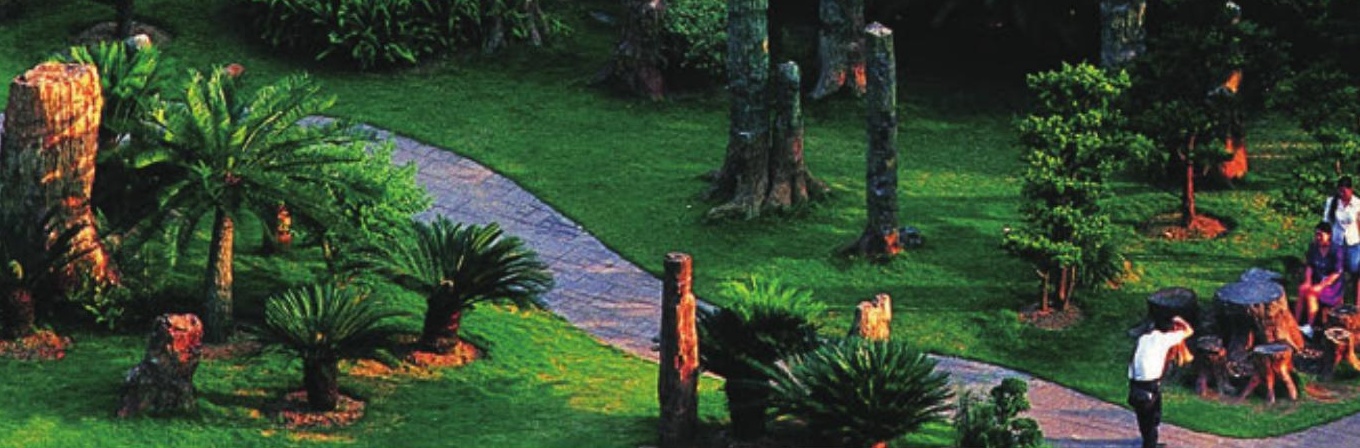


